\title{
Effect of Heat Input with Current Variation on Weld Overlay GTAW Method with ERNi-CI and ERNiFe-CI Fillers on Mechanical Properties and Micro Structure of Main Cap Product
}

\author{
Muhammad Ikbal Laisa ${ }^{1, a)}$, Sulistijono², Jatmoko Awali ${ }^{3}$ \\ Material and Metallurgical Engineering, Institut Teknologi Kalimantan, Soekarno-Hatta KM. 15 Balikpapan Utara, \\ Balikpapan 76127, Indonesia \\ a)06131005@itk.ac.id
}

\begin{abstract}
Weld overlay is one of veneering method that do by welding on the base metal, so there is wear resistant, additional layer and corrosion resistant. Vibration load that work continue on engine block causing worn out on the components that be in the engine block, one of which occurs on both sides of the main cap that directly intersect to the engine block, however it needed an appropriate repair method that is weld overlay method that giving additional layer and wear resistant. This research is using filler ERNi-CI dan ERNiFe-CI on weld overlay method GTAW with current variation on main cap that made from nodular cast iron. Trials that did is conducted metallography and hardeness. The observation result of metallography show that micro structure in HAZ area and base metal contain more ferrite on the lower current. The more heat input however the more it decreasing hardeness value on weld metal and fusion line. This is caused by the more heat input, however cooling that happens become slow. The hardeness value of welding filler ERNiFe-CI is more high than the hardeness value of welding filler ERNi-CI effect of influence the numbers of nickel composition on the filler.
\end{abstract}

Keywords: ERNi-CI, ERNiFe-CI, GTAW, Main cap, Nodular cast iron, Weld overlay

\section{INTRODUCTION}

Weld overlay is a coating process which is carried out by welding method which gives weld metal coating on the component so that there is a wear-resistant layer and corrosion-resistant on the component. Weld overlay is often used in the oil and gas industry in pipes, fittings, valves and valves to improve corrosion resistance and then in the automotive and heavy equipment industries such as engine components commonly used to repair damage and improve wear resistance.

The main cap is a component of a diesel engine that is useful to support the cranksaft in the engine block. Main caps that work on the vibrating load continuously cause wear on both sides of the main cap directly to the engine block. The damaged stamp will interfere with the performance of the engine and can damage other components for that required appropriate method to repair wear on the main cap. Repair method that may be used on main cap is weld overlay.

Main cap based nodular cast iron have a high carbon content that has low welding properties which can cause cracking and porosity as well as martensite phase when welded. Therefore, in the process of weld overlay on a Main cap based nodular cast iron there are some that need to be observed, such as heat input (including current, voltage, and welding speed), filler used, and protective gas used. The correct selection of heat input will avoid the welding defects that occur. The heat input change can affect the width of HAZ. The mechanical properties and microstructures can also change due to parameter changes (Jenney, O’Brien, American Welding Society., \& Welding Handbook Committee., 2001). As for some commonly used weld overlay method that is SMAW, SAW, 
GTAW, GMAW and others. The use of GTAW methods can be used with several advantages that minimize the width of HAZ, can be used on small areas and good welded results without slag and slag.

GTAW (Gas Tungsten Arc Welding) is a type of electric weld that uses the electrode is not consumed. The electrode used in this method is only to generate an electric arc. Inert gases (such as Argon, Helium) and carbon dioxide as protective gases to prevent oxidation. This method uses additional material in the form of filler (rod) (DED (German Development Service), 2000). Filler used in cast iron is a filler based on nickel alloy which is useful to prevent cracking after welding.

The results of previous research is the analysis of the welding properties of nodular cast iron using 2 types of electrodes and welding methods. Shield Metal Arc Welding (SMAW) and Acetylene Welding (OAW) used, with and without preheating, in a casting sample $(300 \times 90 \times 5) \mathrm{mm}$ without groove using two types of electrodes: Fe-Cr$\mathrm{Ni}, \mathrm{Ni}-98 \%$ And two types of gray iron rods. The results of this study, nodular cast iron can be welded with and without preheating but the mechanical resistance of the joint is worse than the nodular cast iron. When using OAW with gray iron rods the mechanical properties of connections are lower than the parent metal, whereas if SMAW Ni or stainless electrode is used, increased ductility is obtained, which can guarantee no fragile properties in welds (Pascual, Cembrero, Salas, \& Martínez, 2008). Then in the research the effect of mechanical properties of weld overlay cladding of $0.35 \%$ C carbon steel with E309-16 and E316-16 electrode showed strength and hardness increase but decreased toughness of steel (Irwan, 2012) and on GTAW weld overlay research with filler based alloy Nickel in nodular cast iron also improved its wear resistance (Arabi Jeshvaghani, Jaberzadeh, Zohdi, \& Shamanian, 2014).

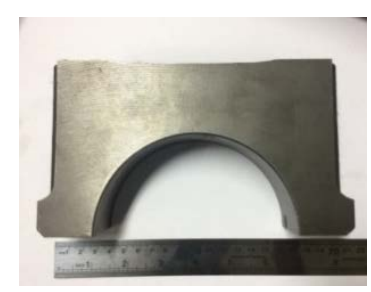

FIGURE 1. Main cap

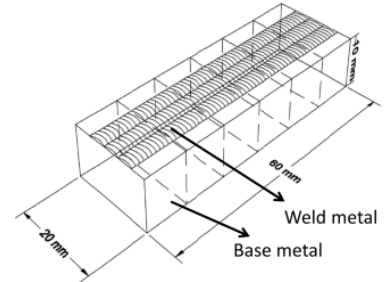

FIGURE 3. Weld overlay design

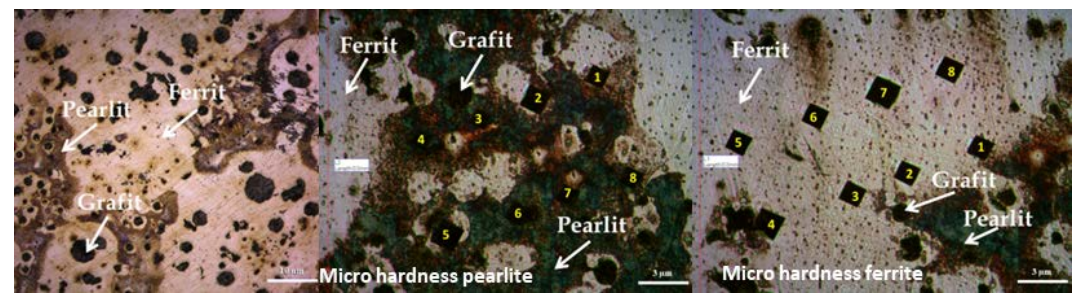

FIGURE 2. Microstructure main cap (nodular cast iron)

\section{MATERIALS AND METHODS}

\section{Materials and Tools}

The equipment used in this research are GTAW welding machine, Thermo gun, Grinding machine and polishing, chain saw, wire brush, digital scales, grade 500 to 2000 rubbers, and velvet fabrics. While the materials used in this research among others, filler ERNi-CI, filler ERNiFe-CI, aquades, and main cap made of nodular cast iron 65-34512. Can be seen the composition and mechanical properties in tables 1 and 2 .

\begin{tabular}{ccccccc}
\multicolumn{6}{c}{ TABLE 1. Chemical composition and mechanical properties Main cap (nodular cast iron 65-345-12) } \\
\hline $\mathbf{C \%}$ & $\mathbf{S i} \%$ & $\mathbf{M n} \%$ & $\mathbf{P \%}$ & $\mathbf{S \%}$ & Hardness, Brinell & Tensile Strength \\
\hline 2,90 & 2,41 & 0,33 & $\leq 0,06$ & $\leq 0,02$ & $143-207 \mathrm{HB}$ & $\geq 450 \mathrm{MPa}$
\end{tabular}

*) (ASTM, 1999) 
TABLE 2. Chemical composition and mechanical properties of ERNiFe-CI and ERNi-CI

\begin{tabular}{cccccccccc}
\hline Filler & $\mathbf{C}$ & $\mathbf{S i}$ & $\mathbf{N i}$ & $\mathbf{S}$ & $\mathbf{F e}$ & $\mathbf{M n}$ & $\mathbf{P}$ & $\mathbf{C u}$ & Tensile Strength \\
\hline ERNiFe-CI & $\mathbf{0 , 0 6}$ & 0,44 & 57,22 & 0,002 & Bal. & 2,07 & 0,001 & $<0,01$ & $604 \mathrm{MPa}$ \\
\hline ERNi-CI & $\mathbf{0 , 0 1}$ & 0,05 & 99,62 & 0,001 & 0,02 & 0,17 & 0,001 & 0,13 & $482 \mathrm{MPa}$
\end{tabular}

*) (American Welding Society (AWS), 2006)

\section{Main cap data}

In Figure 2 it can be seen that this gray iron gray microstructure has three phases of graphite in the form of nodular, lighter-colored ferritee and darker-colored pearlite. In Table 3 it can be seen that the hardness of the nodular cast iron macro has a hardness range of 83.5 - $88 \mathrm{BHN}$ and the mean hardness is 86.26 BHN.

In table 4 and 5 the main cap microstructure (nodular cast iron) can be seen that the pearlite phase has a greater hardness than the ferritee phase. Pearlite phase has a hardness range of 74 to $107 \mathrm{HRB}$ and its mean hardness is 95 HRB. While the value of ferrite faas range of 61- 93 HRB and the average value of its hardness is 83.75 HRB.

TABLE 3. Macro hardness of main cap (nodular cast iron)

\begin{tabular}{|c|c|c|c|c|c|c|c|c|}
\hline \multicolumn{2}{|l|}{ Indented } & 1 & 2 & 3 & & & 5 & \\
\hline \multicolumn{2}{|c|}{ Hardness Value (HRB) } & 85,3 & 87,5 & 88 & & & 87 & \\
\hline \multicolumn{2}{|c|}{ Average } & & & 86,26 & & & & \\
\hline \multicolumn{9}{|c|}{ TABLE 4. Hardness of pearlite main cap (nodular cast iron) } \\
\hline Indented & 1 & 2 & 3 & 4 & 5 & 6 & 7 & 8 \\
\hline Hardness Value (HRB) & 98 & 82 & 103 & 107 & 74 & 98 & 98 & 100 \\
\hline Average & & & & 95 & & & & \\
\hline \multicolumn{9}{|c|}{ TABLE 5. Hardness of pearlite main cap (nodular cast iron) } \\
\hline Indented & 1 & 2 & 3 & 4 & 5 & 6 & 7 & 8 \\
\hline Hardness Value (HRB) & 87 & 64 & 92 & 93 & 61 & 92 & 92 & 89 \\
\hline Average & & & & 83,75 & & & & \\
\hline
\end{tabular}

\section{Specimen Preparation}

Initial preparation of the main cap material is to cut the main cap material divided into 6 specimens with dimensions of $60 \mathrm{~mm} \times 20 \mathrm{~mm} \times 10 \mathrm{~mm}$. The final preparation prior to welding is to clean the surface of the material from impurities by brushing process in order to avoid inclusion of the slag during the welding process.

\section{Weld overlay process}

In this research, the 2 filler variations are ERNiFe-CI and ERNi-CI. Each filler was varied again by heat current using 75 A, 95 A, 115 A using GTAW welding process. Weld overlay design can be seen in figure 3 . Welding parameters can be seen in table 6 .

\section{Metallographic observation}

In this metallographic test, it is aimed to know the phase, shape and size of micro structure in heat affected zone, Partial Melting Zone (PMZ) and weld metal. It is also to predict the transformation that occurs during the welding process or heat treatment. This test uses the ASM Volume 09 standard with the following steps: first the specimen cutting is done using a chainsaw, the two make the handle to facilitate the grinding of the specimen during the grinding process, the third rubbing the specimen with the silicon carbide sandpaper starting from grade 500 to 2000 so that it will get the surface The fourth, polishing the specimen with the alumina paste in order to make sure there are no scratches on the surface and to dip the surface of the specimen into the etching solution. The etching solution in use was Nital (Nitrit Ethanol) with a concentration of 4\% according to ASTM standard E 407. Finally, the observation stage was performed to observe the microstructure by using optical microscope. This test is performed in the laboratory using an optical microscope. 


\section{Hardness testing}

Hardness testing is performed to determine the distribution of hardness in the base metal, Partial Melting Zone (PMZ), Heat Affected Zone (HAZ), and weld metal. The test was performed using a hardness testing apparatus in material and metallurgical engineering laboratory ITK. The hardness testing standard used is the rockwell method based on ASTM E 10.

\section{RESULT AND DISCUSSION}

\section{Metallographic observation results}

Figure 4.5,6,7,8,9 shows the phase formed on the base metal region after welding ie the pearlite matrix, the ferrite matrix and the nodule graphite. Where pearlite matrix has increased area when compared with pearlite matrix before welding. In the HAZ area shows an increase in the area of the pearlite matrix compared to the base metal region and the slightest visible ferritee surrounding the graphite nodule. Also visible graphite nodules that are in the base metal is smaller than the graphite nodules that are in the HAZ. Then in the fusion line area there is a phase of ledeburit and cementite where the results of this phase microscopy test has high kekersan with a range of 30 HRC to 50 HRC. The cementite and ledeburite phases are formed by rapid cooling. Further phase is formed in the weld region of the austenite and graphite phases.

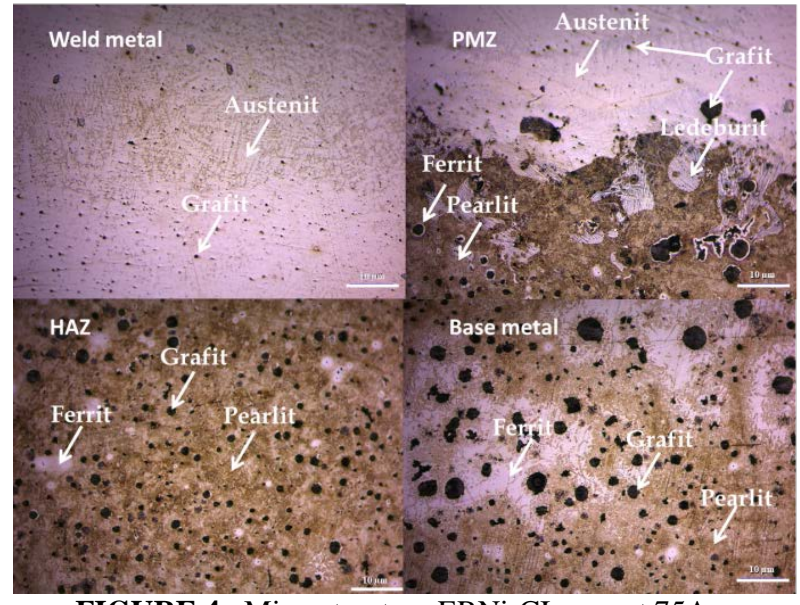

FIGURE 4. Microstructure ERNi-CI current 75A

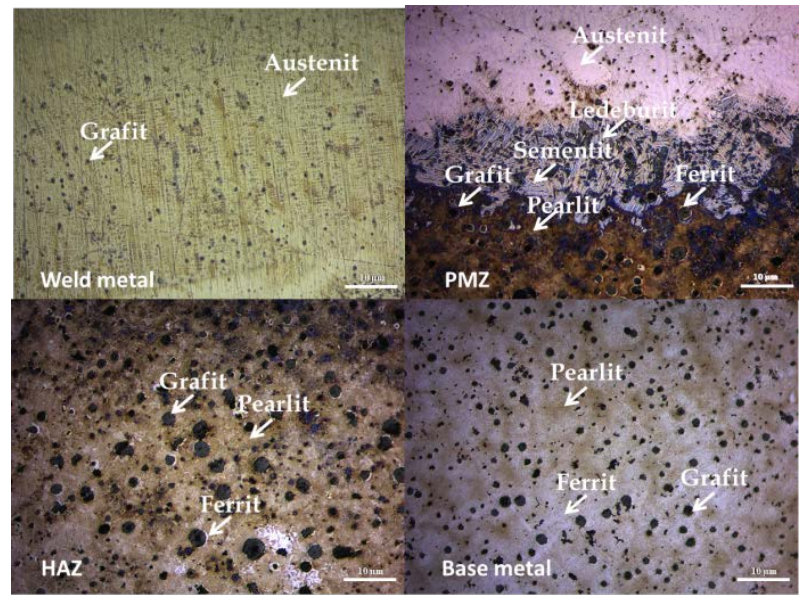

FIGURE 6. Microstructure ERNi-CI current 115 A

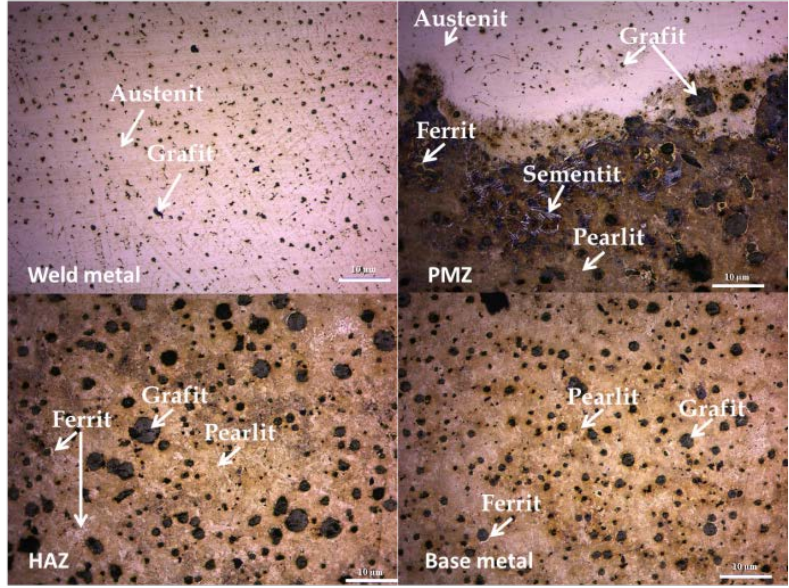

FIGURE 5. Microstructure ERNi-CI current 95A

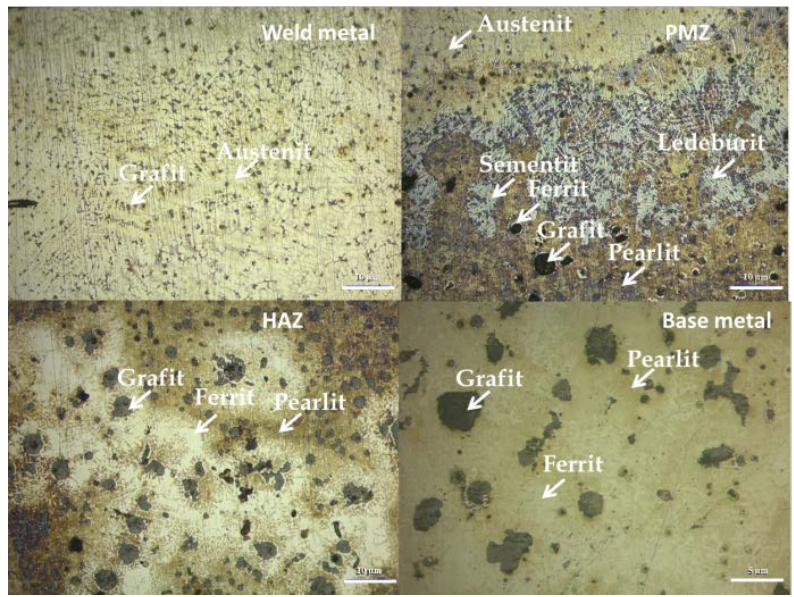

FIGURE 7. Microstructure ERNiFe-CI current 75 A 


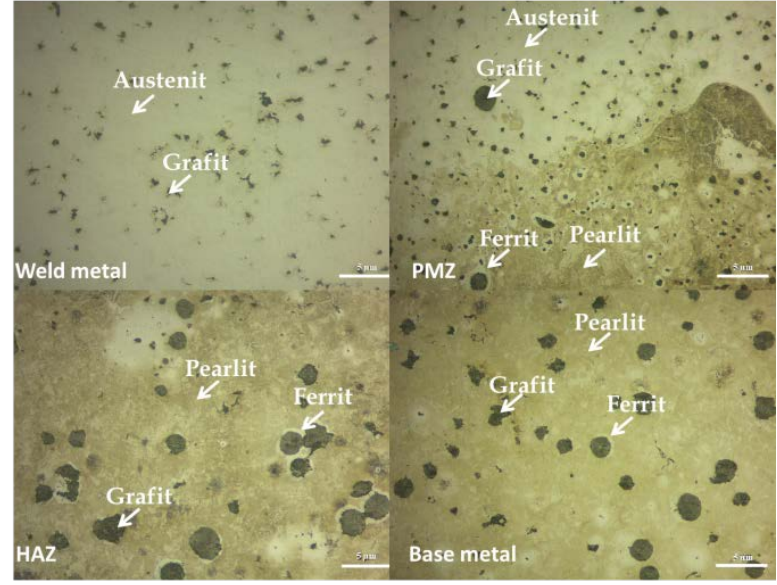

FIGURE 8. Microstructure ERNiFe-CI current 95 A

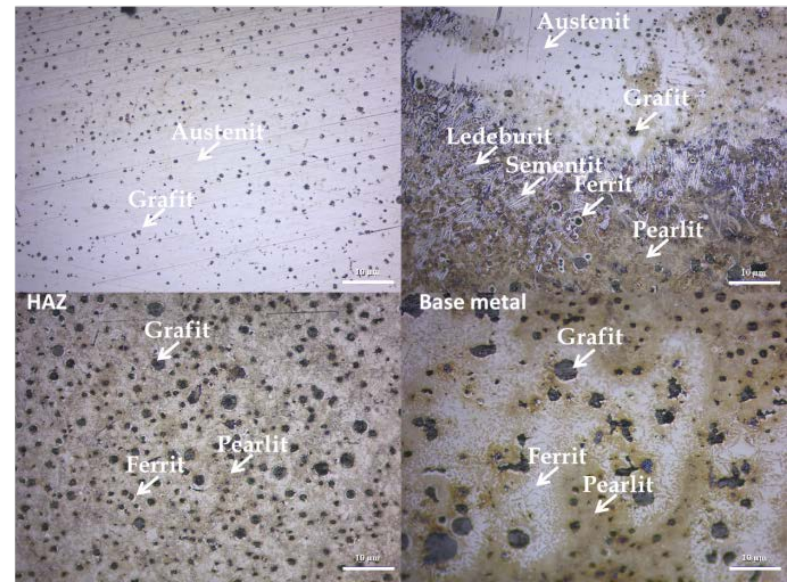

FIGURE 9.Microstructure ERNiFe-CI current 115A

TABLE 6. Welding parameters

\begin{tabular}{cccccc}
\hline Parameter & Voltage (volt) & Polarity & Preheat & Welding position & Shield gas \\
\hline value & 15 & DCEN & $300^{\circ} \mathrm{C}$ & Horizontal-datar & Argon $100 \%$ \\
\hline
\end{tabular}

\section{Result of hardness testing}

Figure 10 shows the hardness of the filler ERNi-CI current $75 \mathrm{~A}, 95 \mathrm{~A}$ and 115A. The ERNi-CI filler showed the highest successive hardness of 75 A, 95 A, 115 A, 105.4 HRB, 104.6 HRB, 98.5 HRB and 96 HRB. Figure 11 shows shows the hardness of the filler ERNi-CI current 75 A, 95 A and 115A.

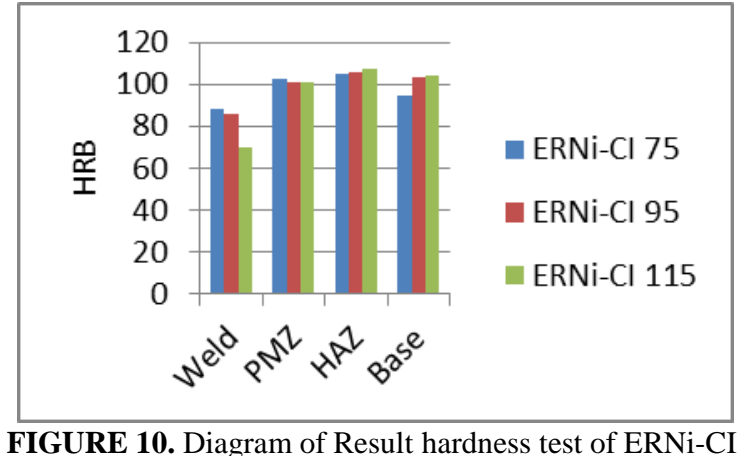

FIGURE 10. Diagram of Result hardness test of ERNi-CI

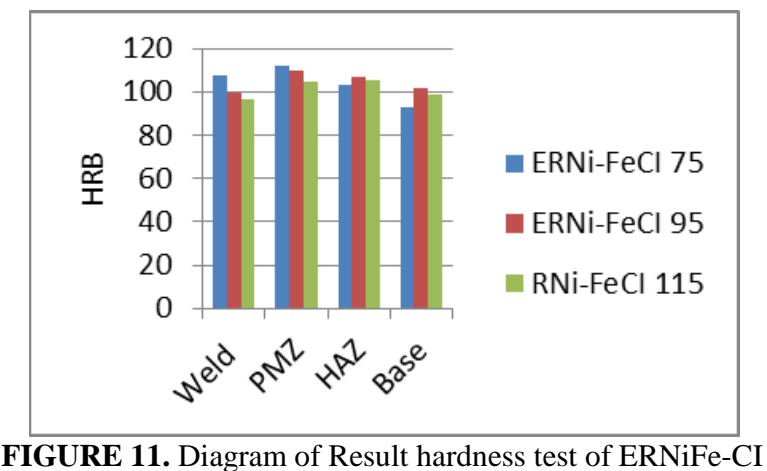

FIGURE 11. Diagram of Result hardness test of ERNiFe-CI

\section{Discussion}

The results of hardness test on ERNi-CI filler showed that the area with the lowest hardness was weld area. In sequence weld area lowest to high that is $115 \mathrm{~A}, 95 \mathrm{~A}$, and $75 \mathrm{~A}$ because influenced by heat input, where the higher heat input hence the slower rate of cooling so that it can influence to its lower hardness characteristic. Low weld hardness in the welding process using the filler ERNi-CI is also terpangaruh result of high levels of nickel which has properties to increase the ductility in the filler. The highest hardness occurs in the fusion line area where there is a ledeburite and cementite phase formed by rapid cooling. Then in the HAZ region its hardness is higher than the base metal region because the HAZ region is the metal part affected by the direct heating effect of the welding process and experienced a rapid cooling rate, so the atoms are distorted which is what increases the hardness value in the HAZ area. This is also evidenced by the image of the microstructure of the HAZ region comprising the pearlite phase dominance formed by the effect of heat input.

The results of hardness test on the ERNiFe-CI filler showed hardness in the weld region relative to hardness on base metal. In sequence weld area lowest to high that is $115 \mathrm{~A}, 95 \mathrm{~A}$, and $75 \mathrm{~A}$ because influenced by heat input, 
where the higher heat input hence the slower rate of cooling which influence to its hardness is lower. The relative weld hardness relative to base metal in the welding process using the ERNi-CI filler is impacted by the nickel content of only 55\% of the filler composition so that it does not increase the ductility if it is compared with the ERNi-CI filler resulting in increased hardness. The highest hardness occurs in the fusion line area where there is a ledeburite and cementite phase formed by rapid cooling. Then in the area of HAZ its hardness is higher than base metal region also due to the dominance of the pearlite phase which formed due to the influence of heat input. In base metal ERNiFe-CI welding process.

\section{CONCLUSION}

Based on the results of the research, the following conclusions can be drawn:

1. The microstructure of the HAZ and base metal at a current of $75 \mathrm{~A}$ is more ferrited than at a current of 115 .

2. The more heat input however it will decreasing the hardness value and fusion line. It caused by the more heat input however the cooling will be slow.

3. The Hardness value of result ERNiFe-CI filler welding process is higher compared than the hardness value of result ERNi-CI filler welding process.

\section{ACKNOWLEDGMENTS}

We thank to Prof. Sulistijono, DEA for his assistance and comments that improved greatly the manuscript. We would like to show our gratitude to Jonas T. from Institut Teknologi Sepuluh Nopember who had given a help to conduct FTIR study.

\section{REFERENCES}

American Welding Society (AWS). (2006). ANSI/AWS A5.15-90 Specification for Welding Electrodes and Rods for Cast Iron. Miami: American Welding Society (AWS).

Arabi Jeshvaghani, R., Jaberzadeh, M., Zohdi, H., \& Shamanian, M. (2014). Microstructural study and wear behavior of ductile iron surface alloyed by Inconel 617. Materials \& Design (1980-2015), 54, 491-497. https://doi.org/10.1016/J.MATDES.2013.08.059

DED (German Development Service). (2000). Gas Tungsten Arc Welding Course. DED (German Development Service).

Irwan, Y. (2012). Pengaruh Sifat Mekanik Hasil Weld Overlay Cladding Baja Karbon 0.35\%C dengan Elektroda E 306-16 dan E 316-16. Institut Teknologi Nasional. Retrieved from http://lib.itenas.ac.id/kti/wpcontent/uploads/2012/11/04.-Pengaruh-Sifat-Mekanik-Hasil-Weld-Overlay-Cladding-Baja.pdf

Jenney, C. L., O’Brien, A., American Welding Society., \& Welding Handbook Committee. (2001). Welding handbook: Welding science and technology (9th ed.). Miami FL: American Welding Society.

Pascual, M., Cembrero, J., Salas, F., \& Martínez, M. P. (2008). Analysis of the weldability of ductile iron. Materials Letters, 62(8-9), 1359-1362. https://doi.org/10.1016/J.MATLET.2007.08.070 